\title{
A Note on Mushroom Immunomodulation and its Potential on Prevention of Cancer
}

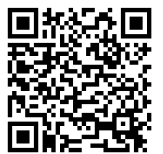

\author{
Bell V ${ }^{1}$, Ferrão $\mathrm{LJ}^{2}$, Chaquisse $\mathrm{EE}^{3}$ and Fernandes $\mathbf{T H}^{4 *}$ \\ ${ }^{1}$ Faculty of Pharmacy, Coimbra University, Portugal \\ ${ }^{2}$ The Vice-Chancellor's Office, Pedagogical University, Mozambique \\ ${ }^{3}$ National Health Institute, Mozambique \\ ${ }^{4}$ Faculty of Veterinary Medicine, University of Lisbon, Portugal
}

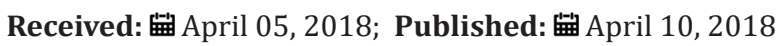

*Corresponding author: Fernandes TH, Faculty of Veterinary Medicine, University of Lisbon, 1300-477 Lisbon, Portugal

\section{Introduction}

Patterns of diseases and resulting well-being, morbidity and mortality have changed considerably in the last decades namely in developed countries. Infection-contagious diseases are no longer a major threat and other chronic ailments such as cardiovascular diseases and cancer are today major factors in lack of health and mortality. In developing countries parasitic and infectious diseases are still major sources of illness while chronic diseases are not so easy to diagnose due to lack of proper equipment, staff and financing. A vast list of clinical, physiopathological, and epidemiological studies has underlined the detrimental or beneficial role of nutritional factors in some chronic diseases such as obesity, type 2 diabetes, cardiovascular disease, and cancer. It has been described that lifestyle, environmental conditions, and nutritional compounds influence gene expression. Nutritional interventions and using low-dose immunotherapy as a foundation to rebuilding healthy immune systems through feeding may change the pattern of chronic diseases. An enormous amount of natural products, foods or dietary supplements, are considered to help to prevent cancer although most lack scientific and consistent evidence performed on experimental and clinical trials.

\section{The Role of Mushroom Nutrition}

Mushrooms are high in antioxidants, just like carrots, tomatoes, green and red peppers, pumpkins, green beans, zucchini, and many other whole foods. Antioxidants are chemicals that get rid of free radicals, a type of chemical that can harm a person's body cells, potentially leading to cancer [1]. Mushrooms of the genus Agaricus are a common folk remedy against cancer. The active ingredients, polysaccharides and protein-polysaccharide complexes containing $\beta$-glucans, have been isolated and shown to have indirect tumor- suppressing activity via an immunological activation [2]. The vitamin D in mushrooms has also been shown to inhibit the growth of cancer cells by contributing to the regulation of the cell growth cycle. The folic acid in mushrooms plays an important role in DNA synthesis and repair, thus preventing the formation of cancer cells from mutations in the DNA [3].

Selenium is a mineral that is not present in most fruits and vegetables but can be found in mushrooms. It plays a role in liver enzyme function, and helps detoxify some cancercausing compounds in the body. Additionally, selenium prevents inflammation and also decreases tumor growth rates. Selenium has also been found to improve immune response to infection by stimulating the production of killer T-cells [4]. The $\beta$-glucan fibers found in the cell walls of mushrooms stimulate the immune system to fight cancer cells and prevent tumors from forming [5]. Germanium is a metalloid trace mineral with no Recommended Daily Amount (RDA) established. It is abundant on the surface of the earth and is in most plants: aloe vera, broccoli, celery, comfrey, ginseng, goji berry, garlic, mushrooms (especially shitake), rhubarb, sauerkraut, suma, seeds, tomato juice and vegetables.

Germanium is believed to be highly beneficial to good human health. In fact, germanium has many important medicinal properties. In the body, germanium attaches itself to oxygen molecules. This has the unexpected effect of making our bodies more effective at getting oxygen to the tissues in our body. The increased supply of oxygen in our bodies helps to improve our immune system. It also helps the body excrete harmful toxins. Germanium is one of the most important reasons why natural foods, such as garlic are recommended by nutritional practitioners [6]. Many disease states, 
such as osteoporosis, heart disease, immune system dysfunction and cancer have all been shown to respond to germanium therapy. Perhaps the most exciting thing about germanium is that it can stimulate the human immune system to fight cancer cells. In fact, germanium is completely harmless to human cells, even cancer cells. Since it works by stimulating our immune system, which fights cancer, it does not damage the rest of the body cells like many other cancer treatments. Testing of new cancer treatments with germanium and its content in mushrooms are underway, and perhaps we will soon see new, less damaging, cancer treatments using the element germanium(Figure 1).

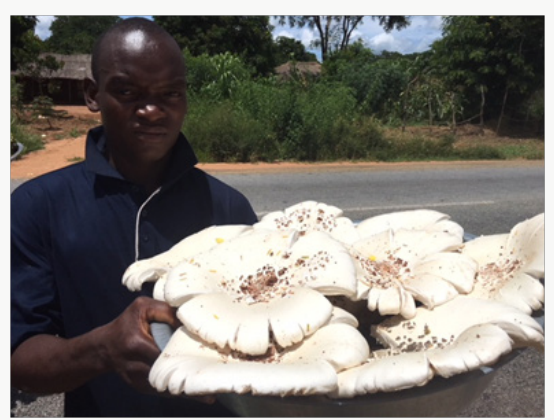

Figure 1: Selling wild mushrooms in Mozambique.

Our team is presently conducting research in this domain on the belief that no scientific data is actually available for claiming health benefits. Wild mushrooms have been part of the human diet for several centuries, but uncultivated wild mushrooms may pose a risk to those unable to distinguish between those safe to eat and those that are dangerous for consumption. In developing countries in Africa, where local medicine covers more than $80 \%$ of the population, consumption of wild mushrooms is advised by native health "doctors" with significant positive results. It is the total diet or overall eating pattern that is most important in disease prevention and achieving good health. It is better to eat a diet with variety than to concentrate on individual foods as the key to good health. Malnutrition in Africa and its whole consequences is also due to lack of food variety and monotonous diet throughout peoples' life.
Increasingly, researchers are taking seriously the possibility that mushrooms may be able to prevent cancer and slow its growth. Chaga (Inonotus obliquus), Lingzhi (Ganoderma lucidum) Lentinan (from Lentinus edodes) are rich in antioxidants, which are chemicals that help prevent cell damage caused by free radicals or oxidants. Triterpenes, the secondary compounds found in mushrooms, cause tumor cells to self-destruct (apoptosis) [7]. Unlike other cancer treatments, however, mushroom does not appear to harm healthy cells. When the body is unable to produce enough antioxidants to prevent this damage, oxidative stress occurs. Oxidative stress can cause cancer and a host of other health problems. Despite the wide and numerous studies of toxic metal concentrations in various environmental and biological samples in Africa, there is limited or no data from literature that addresses the accumulation of heavy metals and metalloids in foodstuffs from soil and the potential health risk to humans through consumption.

\section{References}

1. National Cancer Institute (2015) Antioxidants and Cancer Prevention, USA.

2. Barros AB, Bell V, Ferrão J, Calabrese V, Fernandes TH (2016) Mushroom Biomass: Some Clinical Implications of $\beta$-Glucans and Enzymes. Curr Res Nutr Food Sci 4.

3. O Reilly SL, McGlynn AP, McNulty H, Reynolds J, Wasson GR, et al (2016) Folic acid supplementation in postpolypectomy patients in a randomized controlled trial increases tissue folate concentrations and reduces aberrant DNA biomarkers in colonic tissues adjacent to the former polyp site. Journal of Nutrition 146(5): 933-939.

4. El Bayoumy K (1991) The role of selenium in cancer prevention in Cancer Principles and Practice of Oncology ( $4^{\text {th }}$ edn), Philadelphia, PA, p. 1-15.

5. Chan GC F, Chan WK, Sze DM Y (2009) the effects of $\beta$-glucan on human immune and cancer cells. Journal of Hematology \& Oncolog 2: 25.

6. Siegel A, Siegel H, Siegel RKO (2013) Interrelations between Essential Metal Ions and Human Diseases. Springer, London.

7. Muller CI, Kumagai T, O Kelly J, Seeram NP, Heber D, et al. (2006) Ganoderma lucidum causes apoptosis in leukemia, lymphoma and multiple myeloma cells. J. Leukemia research 30: 841-848.
(C) This work is licensed under Creative

To Submit Your Article Click Here: Submit Article

DOI: $10.32474 /$ OAJOM.2018.01.000113

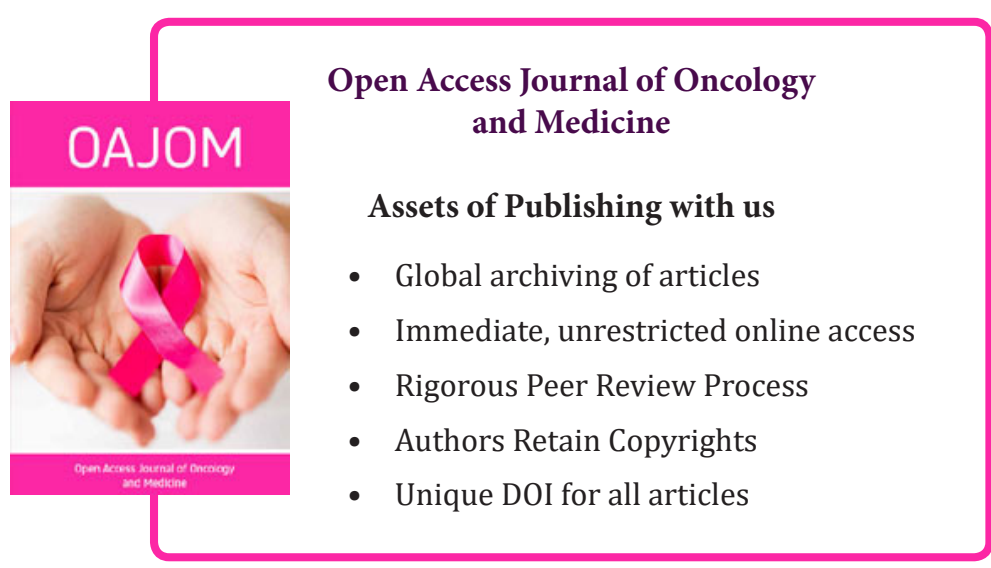

